\title{
ILCEA
}

Revue de l'Institut des langues et cultures

d'Europe, Amérique, Afrique, Asie et Australie

36 | 2019

Représentations de la révolution de 1917 en Russie contemporaine

\section{Représenter la révolution au théâtre (1918-2017) ou comment la locomotive de l'histoire a quitté la voie radieuse}

Staging the Revolution in Theater (1918-2017) or How the Locomotive of History Left the Radiant Way

\section{Marie-Christine Autant-Mathieu}

\section{OpenEdition \\ Journals}

Édition électronique

URL : http://journals.openedition.org/ilcea/6805

DOI : 10.4000/ilcea.6805

ISSN : 2101-0609

Éditeur

UGA Éditions/Université Grenoble Alpes

Édition imprimée

ISBN : 978-2-37747-096-9

ISSN : 1639-6073

\section{Référence électronique}

Marie-Christine Autant-Mathieu, « Représenter la révolution au théâtre (1918-2017) ou comment la locomotive de l'histoire a quitté la voie radieuse », ILCEA [En ligne], 36 | 2019, mis en ligne le 21 juin 2019, consulté le 24 juin 2019. URL : http://journals.openedition.org/ilcea/6805; DOI : 10.4000/ ilcea.6805

Ce document a été généré automatiquement le 24 juin 2019

(C) ILCEA 


\title{
Représenter la révolution au théâtre (1918-2017) ou comment la locomotive de l'histoire a quitté la voie radieuse ${ }^{1}$
}

\author{
Staging the Revolution in Theater (1918-2017) or How the Locomotive of History
} Left the Radiant Way

Marie-Christine Autant-Mathieu

« Nous sommes tous issus de la Révolution... » Il y

a, dans notre art, des thèmes sacrés qui ne vieillissent pas et vers lesquels toutes les nouvelles générations d'artistes et de spectateurs tendent immanquablement. L'un des plus importants est le thème de la Grande Révolution socialiste d'Octobre et de son chef Vladimir Ilitch Lénine. Chaque nouvelle étape historique de notre vie met en valeur de nouvelles facettes de ce thème. Chaque génération cherche des réponses aux questions qui la préoccupent aujourd'hui et s'efforce de voir concrètement le lien entre les époques passées, présentes et à venir. Et le théâtre recherche, pour représenter les années enflammées de la Révolution, des moyens artistiques capables de répondre à ces questions. (Hajčenko, 1983 : 221)

Dans ces lignes écrites quelques années avant la perestroïka par un historien du théâtre soviétique nous voudrions détacher quelques points autour desquels nous articulerons notre réflexion sur la représentation de la révolution depuis 1917. 
D'abord, la sacralisation d'un événement historique qui va générer une panoplie d'images et de symboles, variant très sensiblement au fil des années. Dans le cas de représentations théâtrales, une reconfiguration de la mémoire collective se joue à travers le changement des paradigmes visuels et sonores, et la personne de Lénine, le chef d'Octobre, va devenir très vite centrale dans les commémorations, et se trouver dans un équilibre subtil, et lui aussi changeant, avec l'autre figure sacrée, celle de Staline.

3 Le renouvellement des générations, en particulier au lendemain du XXe congrès en 1956 et de la déstalinisation qui l'accompagne pendant quelques temps, va créer des dissonances dans les grandes messes convenues. Mais les relectures ne viendront pas contester l'importance fondatrice de 1917 pour la construction de l'URSS et de son idéologie socialiste; elles déplaceront les accents, la symbolique, le rituel et ses figures obligatoires.

Le centenaire d'Octobre marquera-t-il une nouvelle étape? Après l'abandon des spectacles commémoratifs à la fin des années 1980, puis une période de diabolisation des figures ayant engendré la violence, les artistes de théâtre semblent vouloir considérer aujourd'hui la période soviétique comme une étape dans l'évolution de l'histoire non seulement russe mais mondiale.

\section{La sacralisation et ses symboles}

5 «Les rues sont nos pinceaux, les places sont nos palettes ${ }^{2}$.» Ces vers fameux de Maïakovski expriment on ne peut mieux la frénésie qui s'empare des militants relayés par les artistes pour entretenir et répandre la foi dans la révolution d'Octobre. Le travail d'agitation engendre de nouvelles formes d'expression qui débordent les lieux consacrés aux représentations pour envahir tout l'espace urbain. Tracts, affiches, drapeaux, banderoles, panneaux multicolores, spectacles et saynètes joués sur les places, les toits des camions, dans les trains ou sur les bateaux d'agitation essaiment dans l'ensemble du pays. Pour une population à plus de $80 \%$ illettrée, les slogans courts, les images colorées, pimentées de légendes humoristiques et lapidaires, font mouche. La théâtralisation de la vie crée la confusion entre le réel et l'utopie, et permet sans doute de supporter la faim, le froid, les épidémies engendrées par la guerre civile. Encouragés par les théoriciens du Proletkult, les travailleurs cultivent leur veine artistique. Souvent sans culture théâtrale, sans technique ni expérience professionnelle, sans moyens financiers, ils bricolent et inventent des petites formes en empruntant aux arts jugés jusque-là mineurs.

6 Parmi les premières formes engendrées par l'effervescence révolutionnaire, les actions de masse se multiplient à partir du $1^{\mathrm{er}}$ mai 1918 dans l'ensemble du pays. Ces célébrations grandioses (Amiard-Chevrel, 1979: 243-276) visent à souder le peuple autour d'événements historiques auxquels certains spectateurs ont réellement participé, mais dont le déroulement réel fut bien plus prosaïque. L'exaltation, l'embellissement, la symbolisation des faits permettent de les grandir, de les sacraliser et de forger le mythe de l'entrée dans une nouvelle ère ${ }^{3}$. Peu à peu, ces énormes attroupements militants seront canalisés, strictement encadrés et ritualisés (parades, défilés) et deviendront des représentations « d'unité et de loyauté » (Koustova, $2017: 32)^{4}$.

7 D'autres formes d'agitprop se développent sur le théâtre du front de l'Armée rouge; à travers les "Journaux vivants» des Blouses bleues qui font écho à l'actualité par des parades, des scènes acrobatiques ou mimées. Les pièces d'agitation (agitki), interprétées 
souvent sur les lieux de travail prônent l'organisation, la discipline, l'hygiène, l'athéisme. Toute cette production inspirée des formes populaires (cirque, guignol, théâtre de foire, loubok, marionnettes ${ }^{5}$ ) vise à expliquer la situation politique intérieure et extérieure, les mesures économiques en liaison avec la guerre civile, à attiser l'héroïsme de masse et la haine des ennemis: koulaks, mencheviks, popes, bourgeois, capitalistes. Avec la révolution bolchevique, le nouveau théâtre quitte les lieux clos des scènes traditionnelles et cherche à inscrire la représentation dans la vie quotidienne, l'actualité socio-politique, à mélanger les publics, à réunir les acteurs et les spectateurs.

Mais cette attirance pour le plein air et les places publiques - qui signifie le décloisonnement de l'art, son désembourgeoisement, son ouverture à tous, au sens spatial et financier du terme (gratuité des manifestations) - ne dure qu'un temps. Car les artistes qui soutiennent le nouveau pouvoir aspirent à créer des formes qui ne soient pas de simples instruments d'agitation. Ils vont œuvrer à l'avènement d'une révolution esthétique, d'un "Octobre théâtral », à l'intérieur des théâtres, qu'ils soient des amateurs liés aux ateliers du Proletkult ou des professionnels, formés sous l'ancien régime comme Meyerhold, Radlov ou Mardjanov ${ }^{6}$ (Zolotnickij, 1976: 82-83).

Exemplaires de la guerre qui oppose dès 1918 le théâtre «bourgeois » et les militants révolutionnaires : les tribulations de Meyerhold et de Maïakovski pour la représentation de la première pièce soviétique : Mystère-Bouffe (fig. 1).

Figure 1. - Mystère-Bouffe de Vladimir Maïakovski, mise en scène de Vsevolod Meyerhold, affiche du spectacle, 1918.

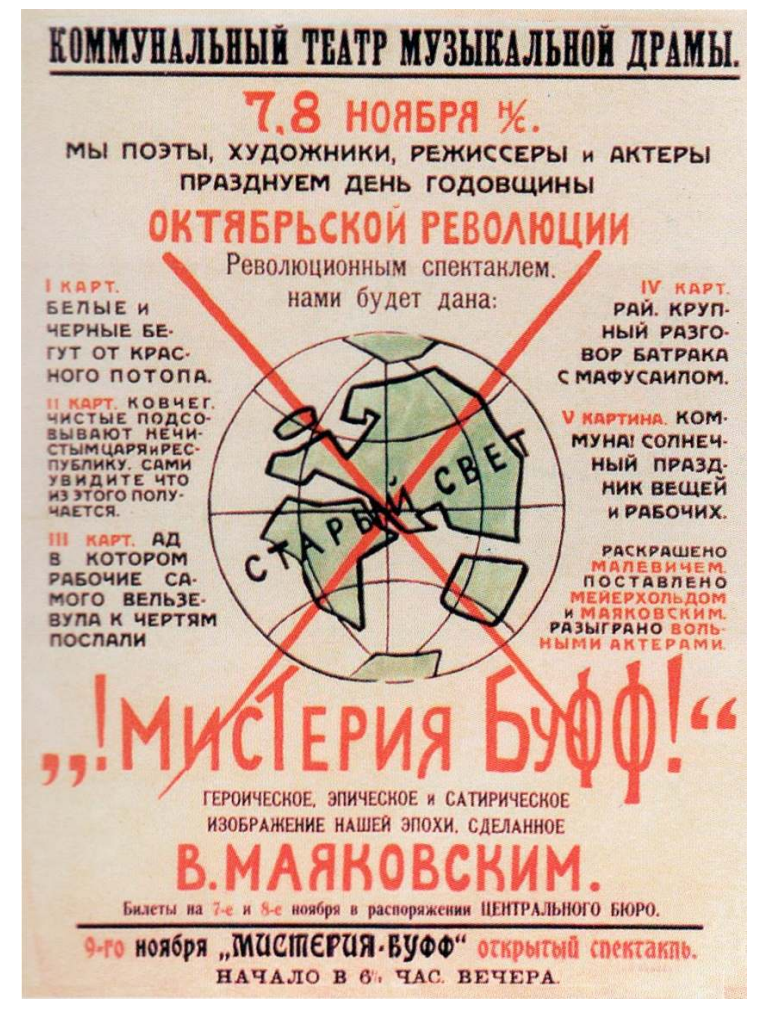

Les comédiens du Théâtre Alexandrinski refusent de jouer la pièce du poète qui parodie le déluge biblique en faisant appel aux slogans des meetings, aux cris de la rue et au langage des journaux. Comment auraient-ils pu accepter, à la fin du prologue, de déchirer le rideau « orné des reliques du vieux théâtre ${ }^{7}$ »? N'ayant pu obtenir le cirque Cinizelli, 
Meyerhold se contente de la salle du Théâtre du drame musical de Pétrograd où le spectacle se donne pour le premier anniversaire d'Octobre. Préparé à la hâte en moins d'un mois, avec des comédiens recrutés par annonce dans la presse, dont certains se désistent à la dernière minute, et avec un personnel technique hostile qui refuse la peinture, la colle et les clous à Kazimir Malevitch, chargé des décors et des costumes (Rudnickij, 1981 : 236), Mystère-Bouffe lance plusieurs défis :

- un défi à la pièce traditionnelle, dotée d'une intrigue et d'un sujet. Dans la deuxième variante composée en 1920-1921, Maïakovski précisera : «Mystère-Bouffe est une route. La route de la révolution. [...] Plus tard, vous tous qui allez jouer, mettre en scène, lire, imprimer Mystère-Bouffe, changez le contenu, faites-le contemporain, actuel, présent.» (1989: 121) ;

- un défi à la troupe théâtrale. Ici les acteurs sont mêlés à des clowns, à des acrobates;

- un défi au jeu psychologique et au long travail préparatoire, prôné dans la plupart des théâtres. Faute de temps pour assimiler le texte, les participants improvisent, jouent parfois deux ou trois personnages (il ne s'agit plus de rôles au sens habituel du terme mais de masques sociaux). Procédant à un renversement carnavalesque (aux Impurs, les Prolétaires, s'opposent les Purs, leurs ennemis de classe, campés en pittoresques figures de guignol), Maïakovski raconte le voyage vers la Terre promise à bord de l'arche, à travers l'Enfer puis le Paradis (fig. 2). Les Impurs en uniformes gris déambulent dans un décor futuriste gris acier, peuplé d'objets pour l'apothéose finale, et font bien pâle figure à côté des diables rouges surgissant des trappes de l'Enfer en faisant la culbute ou des habitants du Paradis accrochés à des nuages en forme de pains d'épice roses, bleus ou rouges.

Figure 2. - Dessin de V. Maïakovski pour les Impurs (les prolétaires).

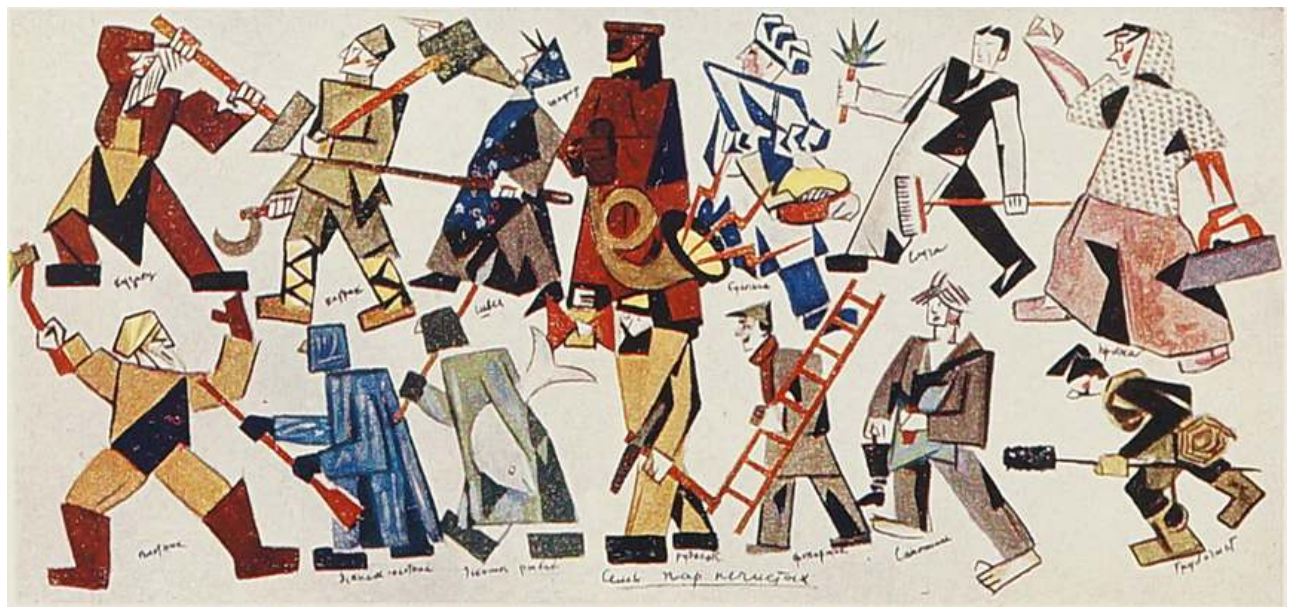

10 Mystère-Bouffe, repris le $1^{\mathrm{er}}$ mai 1921 à Moscou, connaît un succès énorme (la pièce se joue tous les soirs jusqu'au 7 juin). Dans sa nouvelle mise en scène au Théâtre RSFRS-1, Meyerhold supprime le rideau, les coulisses, les décors peints, la rampe : les Objets de la Terre promise sont installés dans les loges. L'action se déroule dans la salle et à différents niveaux du plateau, jusque dans les cintres. Un système d'escaliers et de ponts entoure un hémisphère qui, en tournant, dévoile les trappes de l'enfer. Le cirque et le théâtre de foire sont associés à la revue politique qui dénonce non seulement les adversaires de la Révolution (Clémenceau, Lloyd George), mais aussi les penseurs, comme Rousseau ou Tolstoï, dont les idées sont jugées néfastes. Un conciliateur menchevik, affublé d'une perruque rousse d'Auguste, porte les attributs invariables du capitulard: les lunettes et le parapluie. Au-delà de l'imagerie politique qui renvoie aux affiches ROSTA, Meyerhold et 
Maïakovski fustigent, plus encore que dans la première version, le théâtre-temple, psychologique, voyeur, illusionniste. La représentation ne se déroule pas dans un silence respectueux du travail intérieur des acteurs. Le programme stipule que l'on peut entrer au cours de l'action, manifester bruyamment son enthousiasme ou sa désapprobation...

Meyerhold célèbrera trois autres fois l'anniversaire d'Octobre : en novembre 1920 avec la réécriture de la pièce symboliste d'Émile Verhaeren, Les Aubes qui devient un «spectacle meeting ${ }^{8}$. L'enthousiasme militant génère des trouvailles audacieuses pour ouvrir le huis clos du théâtre sur l'actualité: des tracts sont lancés au public pendant la représentation, des affiches constellent les murs du Théâtre RSFSR-1, un orchestre militaire se joint aux musiciens du théâtre, les acteurs sans maquillage ni perruques, tels des orateurs, haranguent les spectateurs. La lumière reste allumée dans la salle. Meyerhold s'arroge le droit de réécrire la pièce à titre "d'auteur du spectacle " et d'orienter les réactions du public en recourant à la «claque» (zažigateli) : des artistes, installés dans les loges, applaudissent ou sifflent certains orateurs. Une foule de figurants, cachée dans un coin de la fosse d'orchestre, crée l'impression d'une participation du public. Le 18 novembre 1920, lors de la prise de Perekop par l'Armée rouge, Meyerhold vient en scène lire l'annonce de la victoire sur les troupes du général Wrangel ${ }^{9}$ (Rudnickij, 1981 : 251-253). Toutefois, l'actualisation brutale du texte dérouta le public et provoqua l'indignation de Kroupskaï $\mathrm{a}^{10}$. Le spectacle ne resta qu'une saison au répertoire, malgré une seconde variante réalisée un mois après la première. Meyerhold exécutera à nouveau le rituel commémoratif en 1927 en confiant à une "brigade " la mise en scène d'Une fenêtre sur la campagne d'Akoulchine (une pièce de propagande peuplée de joyeux kolkhoziens accomplissant les rituels rouges) et en 1930, en reprenant un spectacle d'agitation de 1924: DE (Objectif Europe), rebaptisé DCE (Objectif Europe soviétique) et transformé en un hymne à la construction socialiste grâce au plan quinquennal (Zolotnickij, 1999 : 205-207).

\section{2. « Léniniana »}

Les symboles révolutionnaires, les personnages types, les images à connotation religieuse ou militaire, tout cet arsenal utilisé au théâtre à partir de 1918 montre les forces antagonistes orientées par des leaders charismatiques, des bolcheviks issus du peuple, souvent ouvriers ou soldats de l'Armée rouge. L'incontournable et centrale figure de Lénine fait l'objet d'allusions, de citations, de tirades enflammées mais demeure invisible. Un concours dramaturgique organisé en prévision du $20^{\mathrm{e}}$ anniversaire d'Octobre en 1936 va changer la donne et permettre son incarnation. Les dramaturges vont pouvoir désormais lui attribuer un discours, les acteurs lui prêter leur corps et leur voix, le public le voir dans son rôle de guide. Pour que ces interprétations ne soient pas sacrilèges, il fallait réunir de délicates conditions. Dans la pièce de Pogodine qui fut sélectionnée, L'Homme au fusil (1937), ce fut un célèbre acteur du Théâtre Vakhtangov, Chtchoukine qui inaugura un cycle spécifique, à l'affiche jusqu'en 1989 : la « Léniniana ».

Cette pièce a engendré un «emploi » nouveau qui consiste à imiter l'apparence (petite taille, calvitie, barbiche rousse), la gestuelle et la prononciation grasseyante de Lénine (fig. 3). L'emploi implique aussi de trouver un équilibre subtil entre la simplicité (apparente) et la grandeur (intérieure) : "Tout était naturel en lui et de ce fait, grandiose. » (Višnevskaja, 1988: 182) ... Cruciale fut la première entrée en scène dans l'histoire du théâtre soviétique de l'acteur interprétant Lénine. Le metteur en scène 
Ruben Simonov avait ménagé un effet de suspens en faisant « apparaître » depuis le fond de la scène, marchant dans un long couloir, un petit homme trapu à la démarche énergique. Le public, stupéfait, se leva et ovationna longuement cette résurrection... (Višnevskaja, 1988 : 184) Poli, à l'écoute, calme, rusé, curieux, intraitable avec ses ennemis politiques, bref mais efficace dans ses remarques, animé d'un «clair sourire » lorsqu'il rencontre des prolétaires... les comédiens se plient aux conventions du genre dont la principale est la présence discrète. Il n'est pas rare que les gens simples qui vénèrent le Chef de la révolution ne le reconnaissent pas lorsqu'ils le rencontrent : ce récit type est au centre de L'Homme au fusil (fig. 4).

Figure 3. - Maquillage d'Alexandre Kaliaguine pour le rôle de Lénine dans C'est ainsi que nous vaincrons ! de M. Chatrov, en présence du metteur en scène Oleg Efremov, 1981.

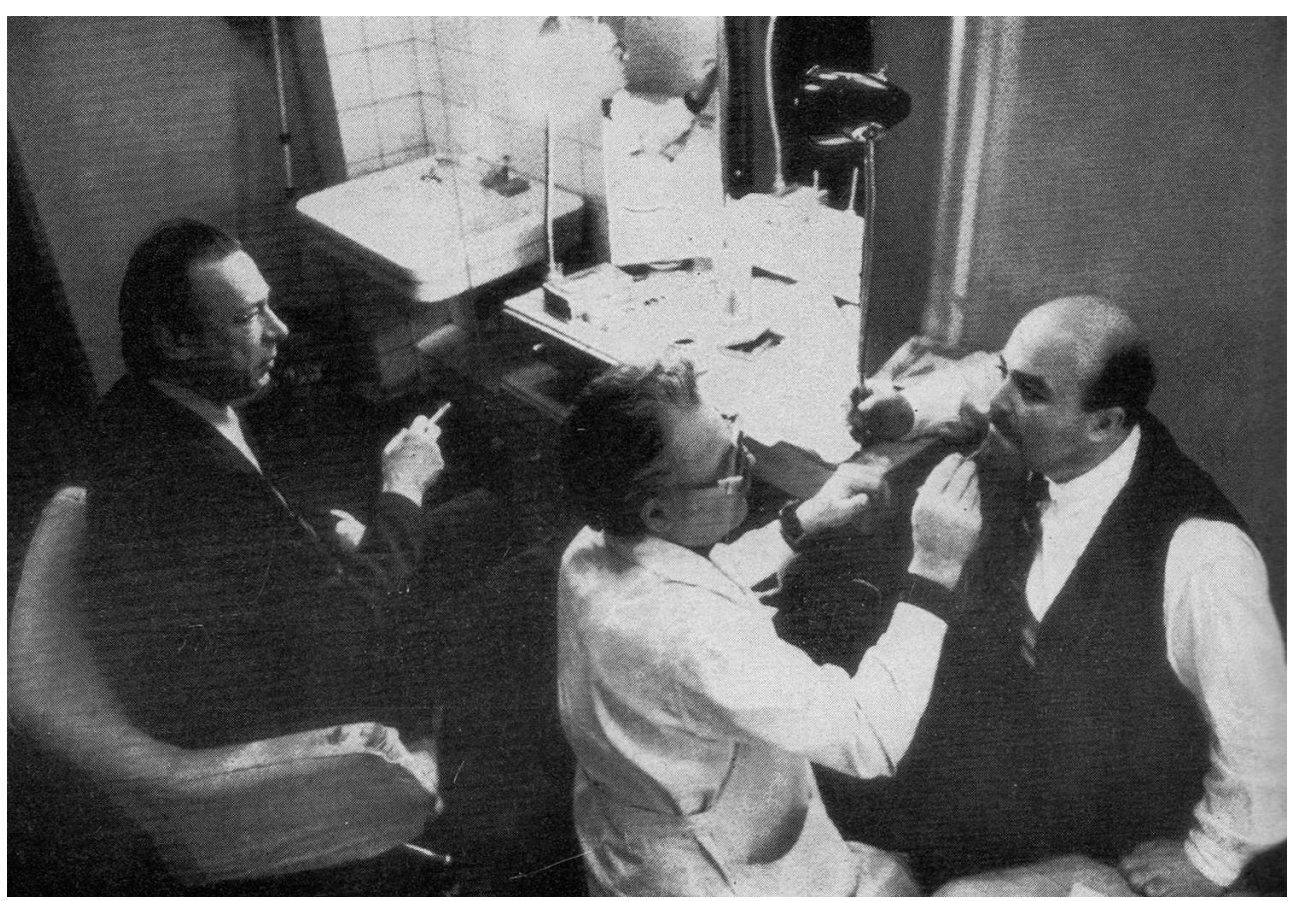


Figure 4. - L'Homme au fusil de Nikolaï Pogodine, mise en scène de Ruben Simonov au Théâtre Vakhtangov, 1937.

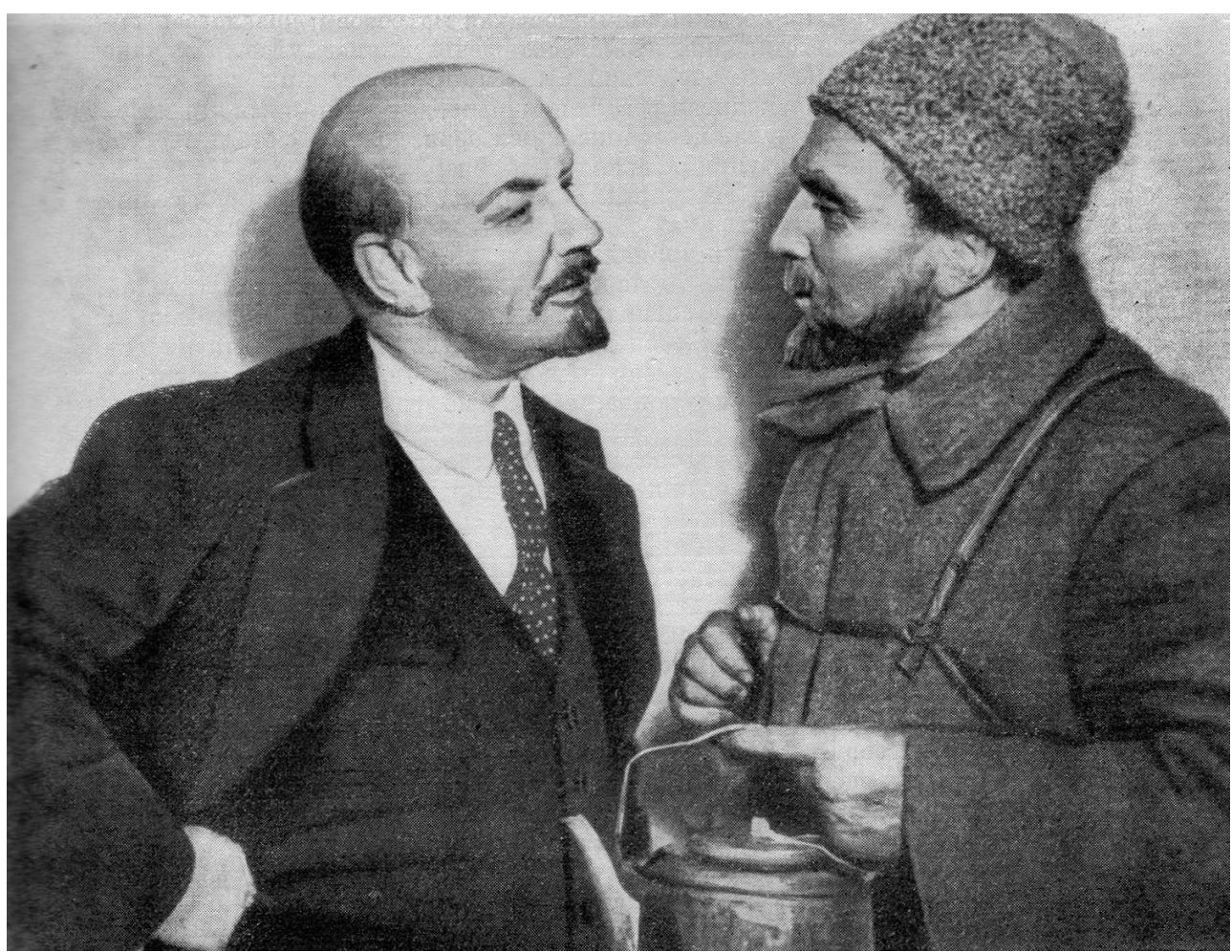

Lénine est interprété par Boris Chtchoukine, le soldat Chadrine par lossif Toltchanov.

Au fil des années, et surtout au fur et à mesure que grandit le culte de la personnalité de Staline $^{11}$, ce schéma interprétatif s'altère. La grandeur cachée de Lénine disparaît. La discrétion se banalise, des acteurs comiques (Ilinski, Kaliaguine) seront pressentis pour jouer le rôle qui consiste souvent à aller à la pêche, semer à la tête d'un artel de paysans, distribuer des jouets aux enfants et lancer de fines plaisanteries... Le culte de Staline s'érige sur une magnification de sa personne et un rabaissement de Lénine, d'ailleurs son seul interlocuteur possible. Lénine s'est fait homme alors que Staline reste coulé dans le bronze ou le marbre. En 1937, ce dernier reste invisible, c'est au téléphone que Lénine le complimente sur son projet de déclaration du droit des peuples ${ }^{12}$. Au fil des années, Lénine s'excusera de déranger Staline et prendra rendez-vous pour le rencontrer. Dans L'Inoubliable année 1919 de Vichnevski (1949) Lénine apparaît au prologue et cède la place à Staline en lui disant : « Nous comptons sur vous, camarade Staline. »

Après le XX Congrès de 1956, la Léniniana se poursuit avec d'autres objectifs civiques et idéologiques. Sous la plume de Mikhaill Chatrov qui travaille entre fiction et documentation, Lénine sert à déstaliniser la vision de la révolution. Chatrov met au second plan le charisme de sa personne pour se centrer, dans la droite ligne des partisans d'un communisme à visage humain, sur le drame d'idées. 


\section{Les étapes dans la construction de la mémoire d'Octobre}

17 Octobre 1918 célèbre la « Pâque rouge » comme le dira Zinoviev. Une symbolique se met en place qui renvoie, on l'a vu, à une mystique naïve mais aussi, au théâtre, à des formes simples, acrobatiques, valorisant le corps sain et souple, la force du groupe, à tout ce qui fustige le Verbe, l'intellect, les complexes références culturelles. Pendant la guerre civile puis sous la NEP, les premières pièces soviétiques s'appuient sur l'actualité et montrent les affrontements blancs/rouges, petits-bourgeois/prolétaires pour finir sur un inévitable happy end : celui de l'adhésion, au prix de sacrifices personnels, douloureux, aux nouvelles valeurs ${ }^{13}$.

En 1927, la reprise en main idéologique des théâtres s'accentue. Les compagnies dites «bourgeoises » comme les anciens théâtres impériaux ou le Théâtre de Chambre dirigé par Taïrov doivent clairement se rallier, en montant une pièce contemporaine sur la révolution. Stanislavski au Théâtre d'Art, après le scandale provoqué en 1926 par Les Jours des Tourbine de Boulgakov (mettant en scène de sympathiques gardes blancs), doit impérativement rattraper cette bavure par une œuvre prouvant la loyauté de la compagnie au régime. Ce sera Train blindé 14-69 de V. Ivanov dont le succès, ostensiblement encensé par la presse, calmera les tensions (fig. 5). À prix fort, car les artistes doivent faire allégeance en renonçant au principe stanislavskien qui a été, jusqu'ici, leur guide dans la préparation des personnages : « Lorsque tu joues un méchant, cherche ses bons côtés. » Il leur faut ici, conformément à la lutte de classe, jouer des personnages positifs (Katchalov est distribué pour la première fois dans le rôle d'un paysan partisan des rouges) ou négatifs (Knipper-Tchekhova peine à incarner une grande-bourgeoise revancharde, pleine de haine). Les comités de contrôle imposent un renoncement à la tolérance, ce péché des intellectuels : les comédiens sont amenés, du moins sur la scène, à liquider sans états d'âme les ennemis de la révolution, ce que olga Knipper, la célèbre interprète des pièces de Tchekhov, tente de contester... (Hajčenko, 1983 : 44-52 ; Gorčakov, 1952 : 467-526) 
Figure 5. - Train blindé 14-69 de Vsevolod Ivanov, mise en scène de Konstantin Stanislavski au Théâtre d'Art de Moscou, 1927.

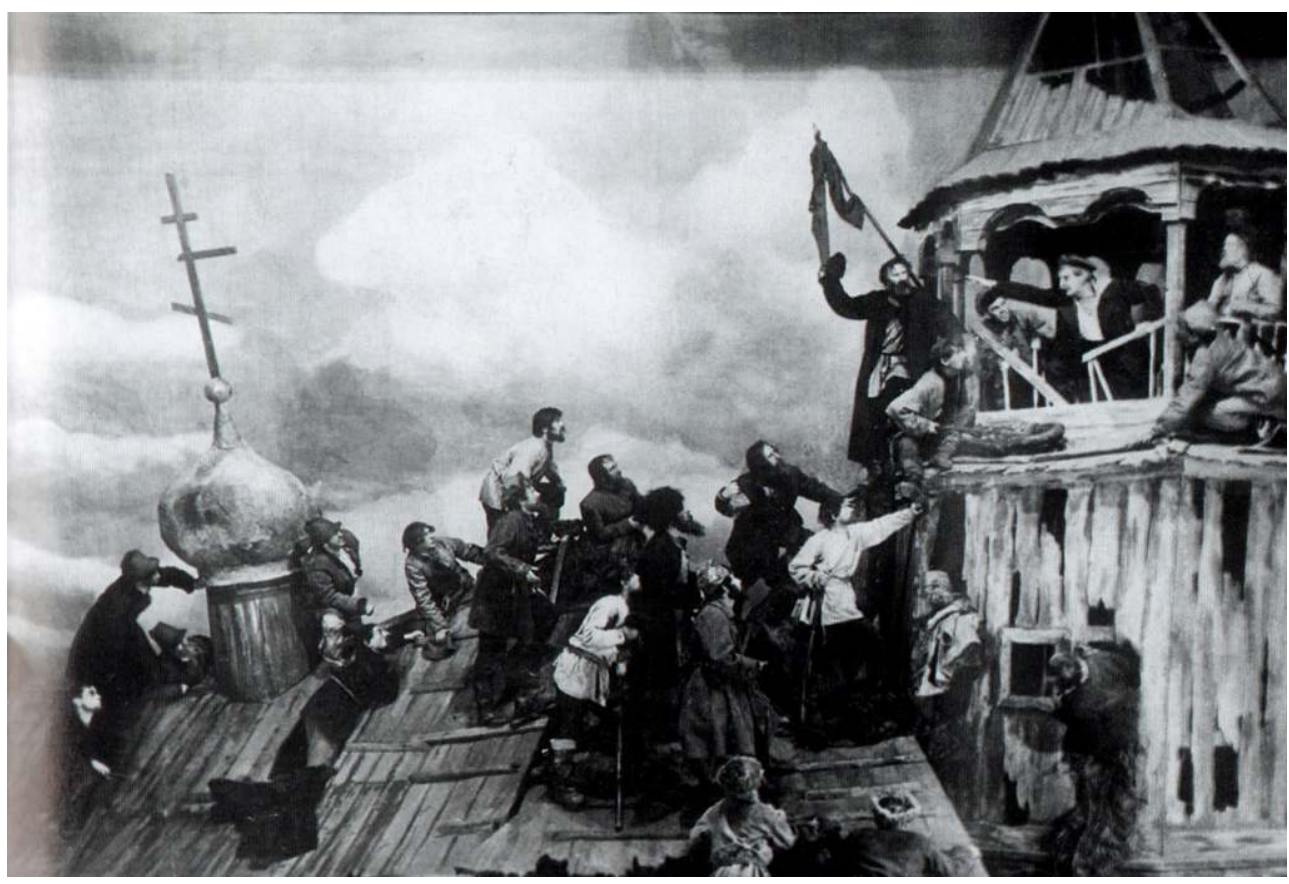

Décors de Viktor Simov pour la scène de foule sur le clocher, acte III, scène 1.

Dès lors, une mémoire manichéenne, et surtout de plus en plus réductrice et schématique, des événements révolutionnaires se met en place. Elle fonctionnera avec des nuances (sur les faits, les personnages, les lieux mis en valeur), mais s'articule autour d'un invariant : la victoire des héros positifs, ce qui oblige les artistes à mettre ce nouvel emploi à leur actif.

En 1937, la mythologie avec ses martyrs, ses rituels, ses démons, est cultivée dans tous les théâtres. Si les innovations formelles se faisaient rares déjà en $1927^{14}$, en 1937, après la campagne contre le formalisme, elles sont totalement exclues. La normalisation de la mémoire et de son expression artistique est à l'œuvre.

1947 : les théâtres reprennent inlassablement les clichés d'un Staline omniscient qui a renversé l'Ancien Régime et qui vient de remporter la «GGP » (abréviation consacrée pour Grande Guerre patriotique). La fonction de tous les spectacles, qu'ils commémorent ou pas Octobre, est de célébrer le Grand Timonier et d'inciter à la vigilance pour identifier et dénoncer les ennemis intérieurs et extérieurs.

C'est seulement à partir de 1956 que les représentations d'Octobre vont donner lieu à des relectures et à une volonté de revenir aux idéaux de 1917, bafoués par le stalinisme. Une certaine souplesse dans les dates des représentations commémoratives se met en place et des spectacles sur Octobre et son environnement peuvent être donnés à l'occasion de la fête de la victoire ou lors des sessions des congrès du PCUS. Dans les principaux théâtres de Moscou et Léningrad, dirigés par des artistes « soixantards ${ }^{15}$ » (Tovstonogov, Efros, Efremov, Lioubimov, Zakharov), le public est convié à une réflexion sur la possibilité d'une autre voie de développement du socialisme.

Symboliquement, les délégués du $\mathrm{XX}^{\mathrm{e}}$ Congrès seront les premiers spectateurs de la reprise des Carillons du Kremlin de Pogodine au Théâtre d'Art, présentée dans une nouvelle 
version scénique qui dépoussière la version de 1942, tout d'abord en l'expurgeant du personnage de Staline. Interprété par Boris Smirnov, Lénine, fidèle au « testament » qu'il a laissé et qui va recevoir une certaine diffusion, affiche son aversion pour la grossièreté et la violence dans ses rapports avec ses collaborateurs et refuse de considérer ses goûts et ses avis personnels comme étant les seuls justes et donc à les rendre obligatoires pour tous ${ }^{16}$.

Le 25 novembre 1955, au BDT de Leningrad, Tovstonogov reprend La Tragédie optimiste de Vichnevski créée en 1933 par Tairov comme une «tragédie monumentale (AutantMathieu, 2011 : 104-112). Reprenant l'idée d'un dispositif stylisé, le metteur en scène met à distance les événements historiques en les ancrant dans une mythologie des origines (la pièce, comme les tragédies antiques, se déroule en Tauride). Les personnages, grâce à des sortes d'arrêts sur images, deviennent des figures transcendantes. La lutte concrète, politique, entre marins anarchistes, officiers de l'Ancien Régime et bolcheviks devient un combat entre les forces lumineuses du Bien et du Mal.

Les pièces de Chatrov, qui alimentent la déstalinisation, donnent un nouveau souffle à la "Léniniana ", car l'auteur déplace la mythologie à partir d'une relecture des événements appuyée sur des documents d'archives. La trilogie présentée par le Théâtre Sovremennik pour le cinquantième anniversaire d'Octobre en 1967 interroge la légitimité de la terreur révolutionnaire à travers l'histoire russe, en 1825 (Les Décembristes de Zorine), 1881 ( Les Membres de la Volonté du peuple de Svobodine) et 1918 (Les Bolcheviks) (Vaissié, 2012: 210 ; fig. 6). Dans cette dernière pièce, Chatrov combat le « communisme de caserne ", la bureaucratie, qui selon lui, ont détruit l'héritage de Lénine. Comme tous les « soixantards », il milite pour revenir aux origines pures du communisme. L'auteur, dont le père et la mère ont été broyés par la terreur de 1937, fait de Staline l'incarnation du $\mathrm{Mal}^{17}$. Chatrov consacrera près de dix pièces et 25 ans de sa vie à Lénine dans la révolution. Dans cette « dramaturgie de l'histoire » (Efremov, $1992: 181$ ), il fait dépendre l'avenir de la façon dont on réfléchit sur le passé (Chatrov, $1983: 247)^{18}$. 
Figure 6. - Les Bolcheviks de Mikhaïl Chatrov, mise en scène d'Oleg Efremov au Théâtre Sovremennik, dans le cadre d'une trilogie pour le cinquantenaire d'Octobre 1917.

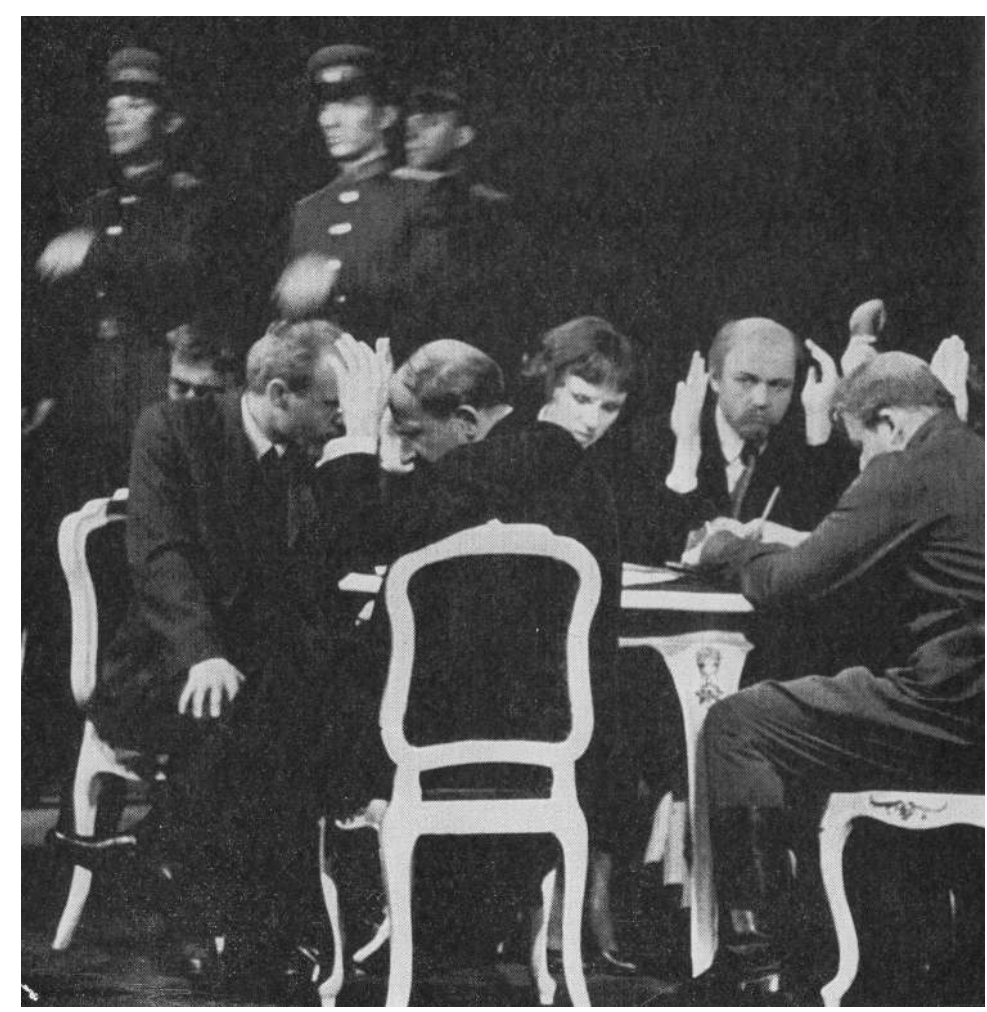

1987: le dernier anniversaire d'Octobre est encadré de deux de ses pièces, caractéristiques de la perestroïka et de la ligne de Gorbatchev : La Dictature de la conscience , 1986 (jouée au Lenkom) et Plus loin... plus loin... plus loin, prévue pour le 70 anniversaire d'Octobre au Théâtre d'Art ${ }^{19}$. Ces spectacles seront au centre des débats sur la légitimité d'Octobre, sur les réformes à mener, et les positions de Chatrov, jugées trop peu radicales par certains, seront condamnées comme antimarxistes par d'autres qui accusent le dramaturge de vouloir mettre en cause «toute la période du développement socialiste » (Vaissié, 2009 : 112).

Au Théâtre du Lenkom, Mark Zakharov crée La Dictature de la conscience sur le principe du collage/montage, de l'improvisation et du dialogue avec la salle (les acteurs circulent avec des micros en interrogeant le public). Réclamant désormais non le martellement de slogans mais la transparence (glasnost) en utilisant le recul temporel pour réfléchir au bien-fondé de telle ou telle décision, le metteur en scène et son équipe d'acteurs extrêmement populaires (ce qui renforce la complicité avec la salle) enquêtent, relient les thèmes proposés par Chatrov avec l'actualité brûlante et attirent le public dans le jeu (Autant-Mathieu, 1987 : 87-88).

Dès le début des années 1990 , le consensus social va se construire sur le rejet du communisme. Le passé soviétique s'estompe des mémoires. Février se confond avec Octobre 1917 et selon les sondages, la révolution est considérée comme un cauchemar, une maladie sociale ou la fête des opprimés ${ }^{20}$. Les théâtres se privatisent, perdent leur fonction éducatrice, s'ouvrent aux divertissements. Les pièces publicistes de Pogodine, Korneïtchouk, Zorine, Vichnevski, Chatrov quittent les scènes pour les bibliothèques. La dramaturgie soviétique elle-même disparaît de la scène qui s'émancipe et se tourne vers 
les recherches formelles en s'inspirant des expériences post-modernes et postdramatiques venues de l'Occident.

\section{Fissures dans le rituel commémoratif}

La représentation de la révolution a pris, on l'a vu, dès 1927 une fonction commémorative immuable visant à célébrer sans fausse note un moment fondateur de la construction de l'URSS. Il ne s'agissait pas d'un spectacle ordinaire, mais d'un moment solennel où le public était convié, souvent sans payer son billet. L'État était prêt à encourager des célébrations financièrement déficitaires mais idéologiquement utiles. L'auteur, dont la pièce avait été minutieusement vérifiée par la censure, confortait sa place dans la nomenclature d'une élite loyale (Smeljanskij, 2002: 357) ${ }^{21}$, les comédiens, triés sur le volet, exécutaient leur devoir civique, le metteur en scène, s'il réussissait à obtenir un consensus laudatif de la critique, plaçait son théâtre sous les meilleurs auspices.

J'ai évoqué ailleurs les entorses au rituel perpétrées dans les années 1920, notamment par les pièces de Boulgakov: Les Jours des Tourbine (1926) et L'île pourpre (1928) (AutantMathieu, 2012). Je voudrais m'attarder ici sur la mise en scène, en avril 1965, d'une adaptation très libre du livre de John Reed, Les Dix jours qui ébranlèrent le monde, paru en 1919 et préfacé par Lénine. Iouri Lioubimov signe alors une déclaration de guerre au réalisme naturaliste et illusionniste qui encombre les scènes soviétiques et revendique le droit à une inventivité formelle dans le cadre d'un théâtre politique (inspiré de Meyerhold et de Brecht) et poétique (dans le sillage de Maïakovski).

En réaction à une image mensongère de la révolution, à une construction mythologique au pathos fabriqué, Lioubimov dans ce spectacle situé au tout début de son parcours (la Taganka a été inaugurée en avril 1964) souhaite montrer le peuple actif dans la création des changements. Profitant de la réhabilitation des avant-gardes des années vingt qui a eu lieu depuis 1956, il renoue avec l'esprit des trains d'agitation, des Blouses bleues, des fenêtres ROSTA, puise dans les procédés du music-hall, du cirque, des variétés (Abeljuk, 2007 : 50-51). Il recourt au mime, au théâtre d'ombre (fig. 7), au rideau de lumière pour découper l'espace, à la symbolique des couleurs, aux masques grotesques: Kerenski, déguisé en femme, s'enfuit à califourchon sur les épaules d'un bourgeois, les ministres du gouvernement provisoire ne se déplacent pas sans leurs valises, leurs discours s'enrayent dans un charabia de théâtre de foire, etc. 
Figure 7. - Les Dix jours qui ébranlèrent le monde d'après John Reed, mise en scène de louri Lioubimov au Théâtre de la Taganka, 1965. Théâtre d'ombres : le nouveau chasse l'ancien.

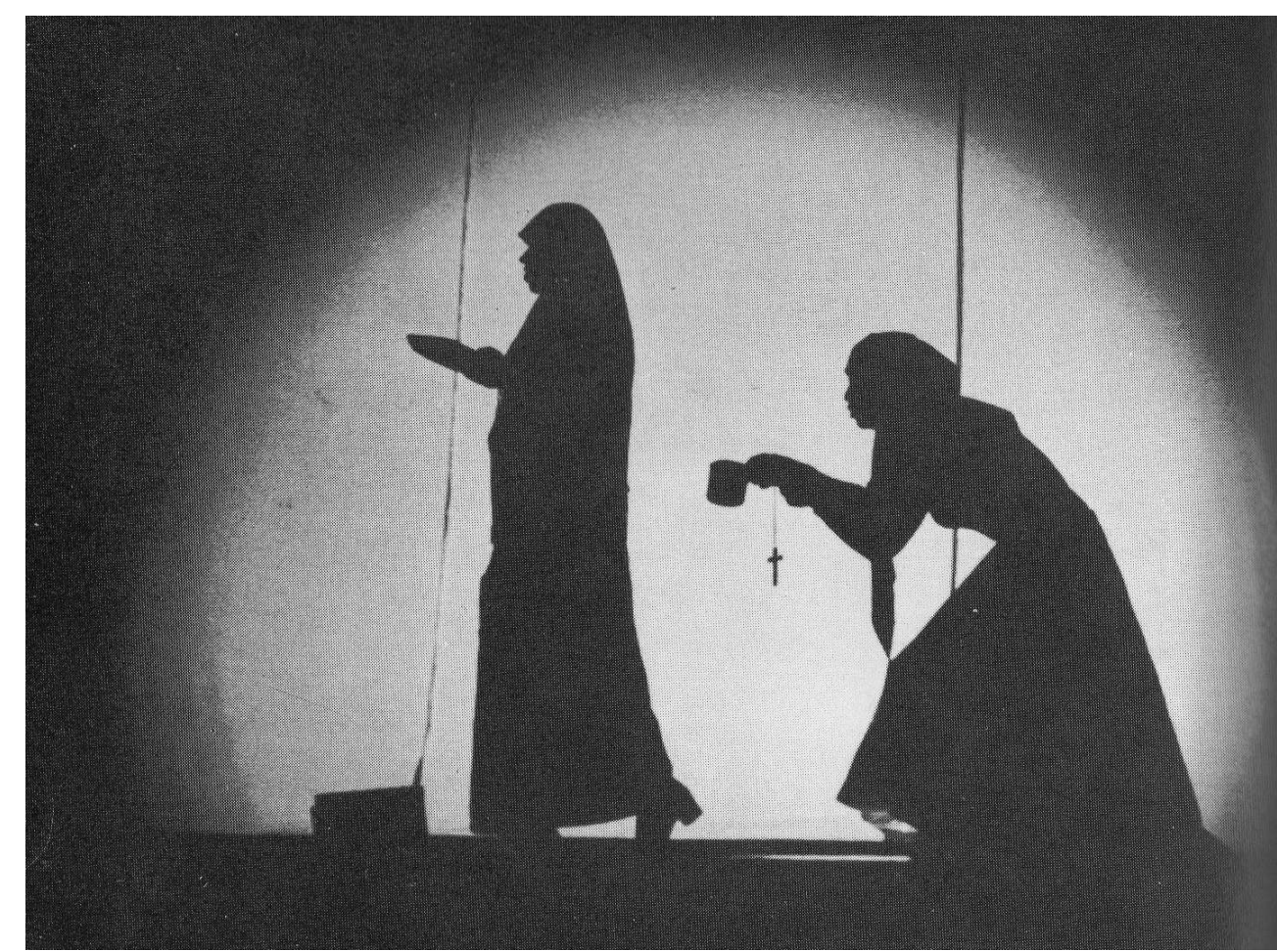

Le spectacle commence dans la rue. À l'entrée du théâtre, un haut-parleur diffuse des chants révolutionnaires, les billets sont contrôlés par des marins et des gardes rouges qui épinglent un ruban rouge à la boutonnière des spectateurs et enfilent les billets sur la pointe de leur baïonnette. Dans le foyer, la foule s'agglutine devant des groupes de marins, de soldats et de filles en fichus rouges qui chantent et dansent. Partout sur les murs, des affiches bigarrées, des calicots rouges portant des slogans écrits dans l'ancienne orthographe. Au-dessus du buffet, une bannière menace les gourmands avec ces vers de Maïakovski : «Goinfre-toi bien d'ananas et d'ortolans! Bourgeois, ton dernier jour est imminent!» (Abeljuk, $2007: 52$ ) Des bulletins de vote sont distribués au public qui les répartit en sortant entre les urnes des " pour» et des « contre ». Les Dix jours lancent un défi au rituel commémoratif d'Octobre, empesé, empêtré dans le respect des valeurs officielles et le culte des chefs. Le spectacle redonne du sens aux mots populaire, démocratique en regardant "la Grande Révolution socialiste d'Octobre " par en bas : il en propose une perception décomplexée, jubilatoire, provocatrice. Le spectacle s'achève sur un clin d'œil à la «tradition »: des moujiki en lapti sont accueillis devant le Smolny par un imposant garde rouge devant lequel ils se découvrent respectueusement. "Nous cherchons, euh, comment dire... » « La vérité ? » demande le garde. « Oui, petit frère, c'est ça, la vérité »... et la salle d'éclater de rire (Gerškovič, 1986 : 91-92).

Malgré le caractère non conformiste des Dix jours, que certains qualifièrent de « cynique ${ }^{22}$ ", le spectacle fut autorisé car il allait à contre-courant des formes convenues tout en restant dans le lit idéologique du discours sur Octobre. Dans une lettre à Brejnev de la fin des années 1968, Lioubimov, alors persécuté par la critique, croit dans un salvateur retour à des origines "pures" et à une victoire sur la bureaucratie "au nom des principes bolchevistes » : « Nous voulons défendre le style et les traditions léninistes », affirme-t-il ${ }^{23}$ . Dans Les Dix jours, il respecte la symbolique: rubans rouges, drapeaux rouges, fichus 
rouges, flammes rouges, enclume, épaves du vieux monde que les ombres chinoises géantes des gardes rouges chassent sans ménagements (fig. 8). Le metteur en scène établit des ponts avec l'histoire par la projection de diapositives de Lénine dans différentes poses et mimiques, projetées en fond de scène ou sur les murs latéraux. Il évoque aussi un moment marquant de la «Léniniana»: le public entend la voix grasseyante de Chtraoukh, imitant Lénine dans le film de Youtkevitch, L'Homme au fusil.

Figure 8. - Les Dix jours qui ébranlèrent le monde d'après John Reed, mise en scène de louri Lioubimov au Théâtre de la Taganka, 1965. Symbolique révolutionnaire du marteau et de l'enclume.

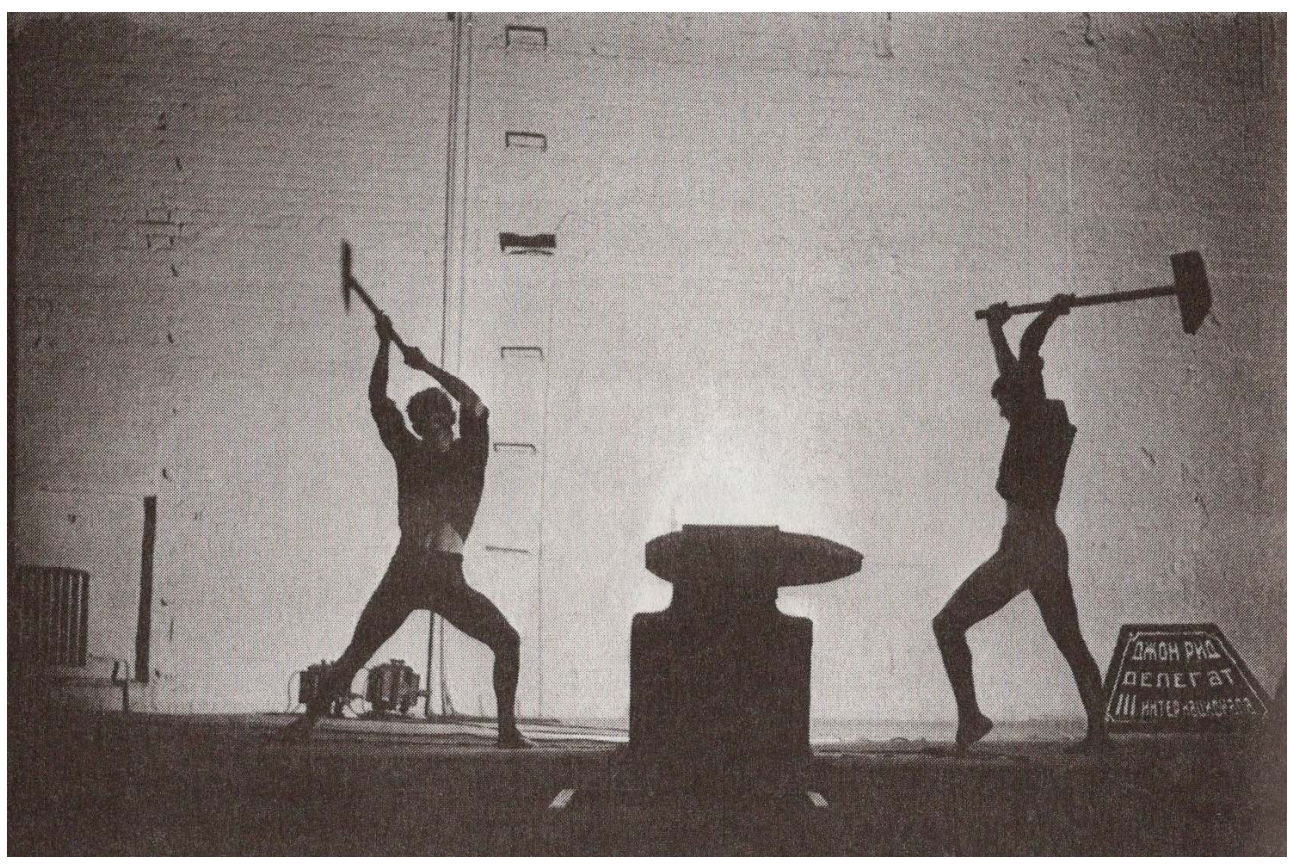

Le metteur en scène considérera plus tard ce spectacle comme « une courbette » devant le pouvoir soviétique ${ }^{24}$. Il a toutefois créé des fissures dans un genre canonique bien rodé, non seulement en ouvrant la voie à la créativité, aux trouvailles scéniques, aux débordements joyeux, mais aussi en déplaçant les dates commémoratives. Les Dix jours sont joués en avril 1965 comme pour fêter la création de la Taganka et rappeler son objectif : déclarer un nouvel « Octobre théâtral » afin de dynamiser les scènes soviétiques. En novembre 1965, c'est par un montage poétique Les Vivants et les morts, que Lioubimov célèbre le vingtième anniversaire de la victoire sur le nazisme, le 9 mai 1945. La mémoire des victimes de la «GGP » venait se superposer au rappel des conquêtes révolutionnaires. Pour le centenaire d'Octobre et en hommage à Lioubimov, né en 1917 et disparu en 2014, Les Dix jours ont été repris en deux soirées au musée de Moscou dans une relecture musicale et plastique de Didenko associé aux acteurs de l'atelier de Brousnikine.

\section{La voie radieuse vers le nirvana}

La discrétion avec laquelle les autorités politiques ont tourné la page des révolutions de 1917 vient de la volonté d'encourager la réconciliation et la paix sociale. À Pétersbourg, berceau des événements de Février et d'Octobre, une soirée de gala intitulée Une leçon d'histoire et donnée le 7 novembre au Théâtre Mariinski, illustrait ces intentions pacificatrices. Entrecoupé de numéros de ballet classique et de chœurs (dont 
ceux des cosaques du Kouban), le spectacle interprété par des écoliers de 2017, s'achevait autour d'une grande table réunissant les jeunes acteurs, leur maitre et les descendants des protagonistes des deux camps. Sous les portraits de Chaliapine, Kerenski, Lénine et Maïakovski, les convives réconciliés promirent « d'accepter notre histoire comme elle est 25 ».

En confiant à un jeune artiste de 25 ans la lourde responsabilité de créer, au Théâtre d'Art de Moscou, un spectacle pour le centenaire d'Octobre, Oleg Tabakov son directeur octogénaire (décédé quelques mois après la création du spectacle), a permis de mesurer le fossé idéologique et artistique qui s'est creusé depuis la fin de l'URSS. Alexandre Molotchnikov a donné une dimension monumentale à La Voie radieuse $19.17^{26}$ en l'encastrant dans une structure qui rappelle les voutes du métro, les cadres d'icônes ou le dôme d'une cathédrale. À partir d'inversions carnavalesques, de décalages qui placent le spectacle entre la science-fiction, le récit merveilleux et le film d'horreur, le jeune metteur en scène restitue, dans un montage de "comix", les images et la symbolique révolutionnaire: La Cavalerie rouge de Malevitch devient un tableau animé et un terrain d'affrontements avec les gardes blancs; les parades sportives recourent à la biomécanique meyerholdienne pour finir en apothéose avec la naissance d'un Homme nouveau (fig. 9). De cocasses raccourcis cristallisent ce qui reste de 1917 dans la tête de la jeune génération. Le héros Makar (ce personnage platonovien va devenir le héros d'un mini-film: Tchevengour, inséré dans le récit scénique ${ }^{27}$ ) s'en va, comme le paysan soldat Chadrine de L'Homme au fusil, chercher de l'eau pour faire du thé. Chemin faisant, il rencontre Lénine, Trotski, Kroupskaïa qui lui implantent un «cœur-moteur ». Le voilà devenu une machine révolutionnaire qui est expédiée par le trio infernal sur les routes pour faire la propagande de l'avenir radieux : Makar ramène des soldats du front, va à la conquête du Palais d'hiver, dékoulakise les campagnes, "prolétarise » l'intelligentsia et chasse les aristocrates dont les rejetons sont supprimés par souci eugéniste. Sa compagne Véra (qui renvoie à l'héroïne du roman favori de Lénine: Que faire?) a quitté le milieu raffiné du ballet pour créer une commune. Elle y côtoie la femme-machine Alexandra Kollontaï qui a réussi à faire passer le décret sur l'amour libre et encourage les prolétariennes logées dans l'hôtel particulier d'un célèbre ténor du Mariinski (compression de surface oblige) à faire la queue pour obtenir ses faveurs... Cette salade russe est rythmée par les à-coups grinçants du cœur machine qui s'emballe parfois, par les discours bredouillés de Lénine-Staline (la transformation à vue ne s'accompagne que d'un changement de voix), par la gestuelle fameuse du chef de la révolution reprise indifféremment par ses partenaires. Les jeunes artistes déballent en vrac l'héritage soviétique, dont ils ont retenu que les cosaques gardant le Palais d'hiver étaient antisémites, que le film Octobre n'était pas un documentaire et que les sources historiques pouvaient être falsifiées ${ }^{28}$. Ils ne se libèrent pas de tabous qu'ils n'ont pas connus. Ils jouent avec la mémoire du passé, devenue un réservoir d'images dépareillées et une source d'inspiration qui a cessé d'être iconoclaste pour alimenter la culture de masse. 
Figure 9. - La Voie radieuse 19.17, mise en scène d'Alexandre Molotchnikov au Théâtre d'Art de Moscou, 2017.

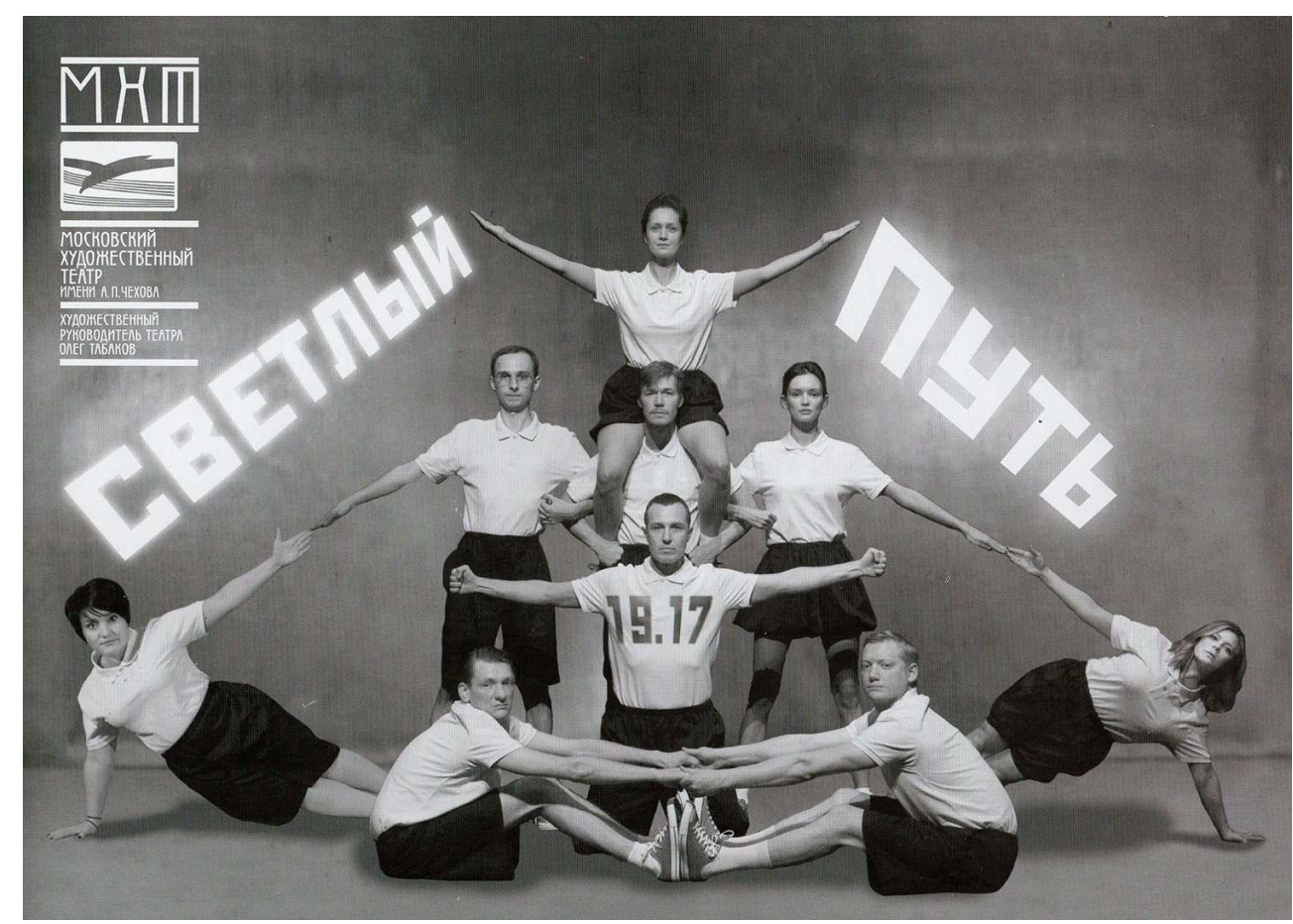

La trépanation de Lénine (Octavia. Trépanation) marquera sans doute une étape dans la réflexion sur 1917. Dans un opéra grandiose, commandé pour le centenaire d'Octobre au compositeur Dmitri Kourliandski et à Boris Ioukhananov, directeur de l'Electroteatr Stanislavski de Moscou, et créé en novembre 2017 à Amsterdam, la tête de Lénine de $7 \mathrm{~m}$ de haut est découpée au laser. Le haut du crâne s'ouvre, les yeux s'illuminent d'un rayonnement hypnotique (fig. 10). Cet espace polyvalent, à la fois praticable, balcon et lieu de projections, surplombe une immense scène où se déploient, dans le rouge, le blanc et le noir, la grandeur et l'horreur de trois régimes tyranniques, à Rome du temps de Néron, en Chine au III ${ }^{e}$ siècle avant J.-C. et en Russie au début du xxe siècle. Les images fantasmagoriques de violence, de mort et de logorrhée absurde, parlée, psalmodiée et chantée, globalisent et détemporalisent la réflexion sur les utopies intellectuelles. Nées de cerveaux surdimensionnés, elles décervellent le peuple pour mieux l'asservir (le peuple chinois est ici figuré par une armée fantôme décapitée qui renvoie aux soldats d'argile enterrés près de Xi'an). Un travail minutieux sur le ralenti (100 fois pour le centenaire !) des premières mesures de La Varsovienne rend l'hymne fameux méconnaissable tout en lui donnant une autre résonance. 
Figure 10. - Octavia. Trépanation, opéra créé à Amsterdam pour le centenaire d'Octobre.

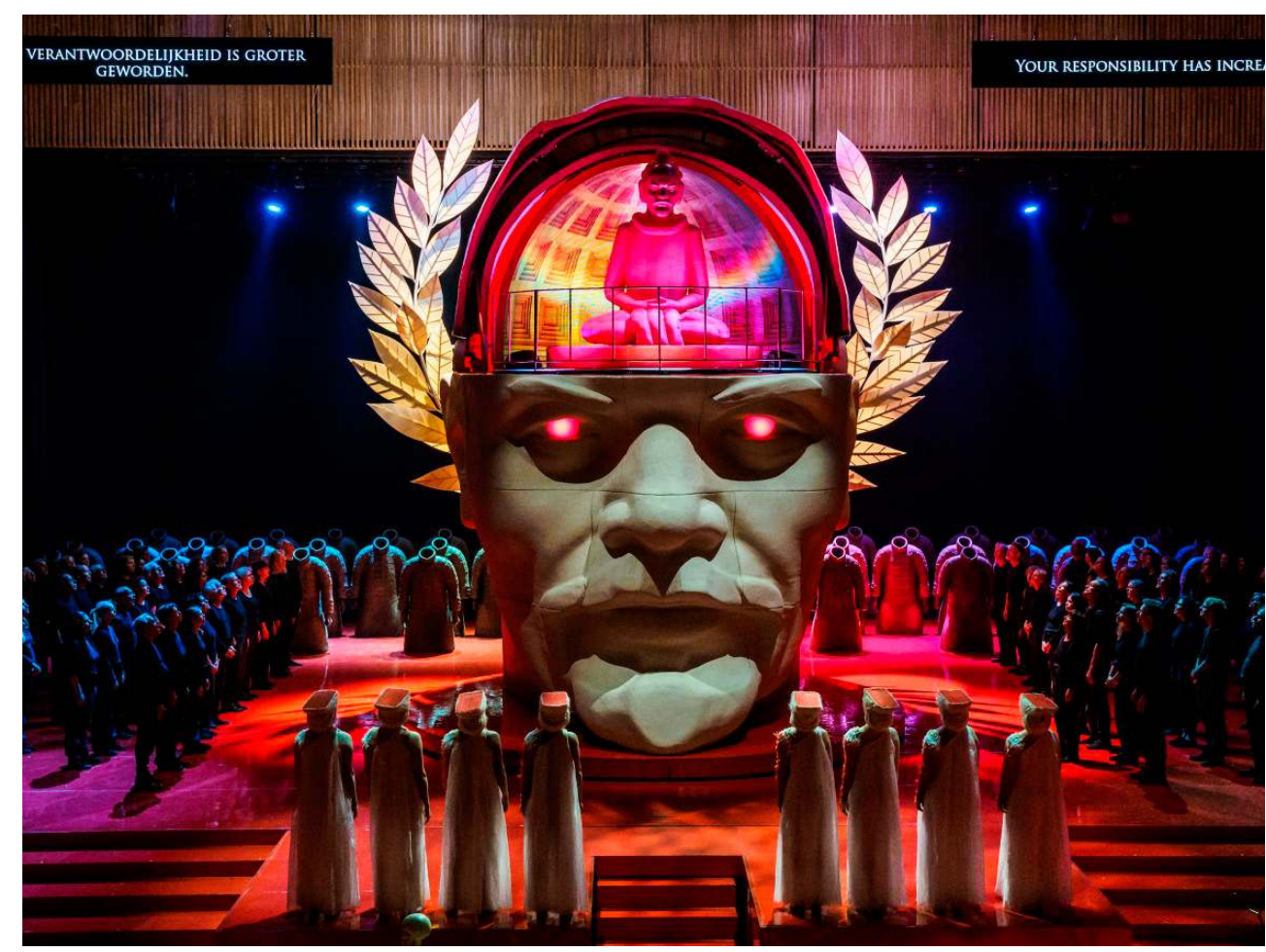

Compositeur Dmitri Kourliandski et metteur en scène Boris loukhakhanov, Electroteatr Stanislavski de Moscou.

Après le culte des révolutions, puis leur diabolisation, le centenaire a-t-il définitivement renvoyé les protagonistes de l'événement dans la mémoire collective? Lénine, Trotski, Dzerjinski ou Kerenski transformés en figures archétypales, perdent leurs attaches historiques, s'éloignent de la mythologique soviétique pour, au gré des visions et des fantasmes artistiques, changer radicalement de caractéristiques. Depuis la perestroïka, les metteurs en scène avaient tendance à présenter Lénine comme un Janus, révélant Staline sur son autre face. Au final d'Octavia. Trépanation, c'est Bouddha qui surgit de la boite crânienne du chef de la révolution russe, comme si le goût pour la tyrannie et la violence pouvait céder la place au détachement du nirvana. Athéna était bien sortie toute armée de la tête de Zeus pour devenir la déesse de la Sagesse...

\section{BIBLIOGRAPHIE}

ABELJUK Evgenija \& LEENSON Elena (2007), Taganka: Ličnoe delo, Moscou : NLO.

Amiard-Chevrel Claudine (1979), « Les actions de masse à Pétrograd en 1920, D. Bablet (dir.),

Mises en scène des années 20 et 30, Paris : CNRS, 243-276. 
Autant-Mathieu Marie-Christine (1987), « Moscou 1987 : Parle ! », Théâtre/Public, juillet-octobre, 76-77, 84-94.

AutANT-Mathieu Marie-Christine (2011), Le Théâtre soviétique après Staline, Paris : IES.

AutANT-MATHIEU Marie-Christine (2012), « Revivre, mythifier ou désacraliser ? La révolution bolchevique et ses représentations au théâtre soviétique (1918-1933) », F. Maier-Schaeffer, C. Page \& C. Vaissié (dir.), La Révolution mise en scène, Rennes : PUR, 132-134.

BoRDJUJOv Gennadij (2017), <https://ru.sputnik.md/columnists/20171031/15329785/9-mairevolytia-novoe-7-noabrea.html> (janvier 2018).

EFREMOV Oleg (1992), Vse neprosto, Moscou : A.R.T.

EFREMOV Oleg (1997), O teatre i o sebe, Moscou : MKhT.

GERŠKOVIČ Aleksandr (1986), Teatr na Taganke 1964-1984, Benson (Vermont) : Chalidze Publications.

GoRČAKOV Nikolaj (1952), Režisserskie uroki K. Stanislavskogo, Moscou : Iskusstvo.

HAJČENKO Grigorij (1983), Stranicy istorii sovetskogo teatra, Moscou : Iskusstvo.

Koustova Emilia (2017), « Manifestation, carnaval, défilé stalinien. Naissance d'une chorégraphie festive (1918-1941) », G. Haver, J.-F. Fayet, V. Gorin \& E. Koustova, Le Spectacle de la Révolution, Lausanne : Antipodes, 31-48.

LJubimov Jurij (2001), Ja. Rasskazy starogo trepača, Moscou : Novosti.

MAIER-SCHAEFFER Francine, PAGE Christiane \& VAISSIÉ Cécile (dir.) (2012), La Révolution mise en scène , Rennes : PUR.

MAÏAKOVSKI Vladimir (1989), Théâtre (W. Wassiltchikov, trad.), Paris : Grasset.

MAJAKоVSKIJ Vladimir (1918), « Prikaz po armii iskusstva », <www.stihi-rus.ru/1/

Mayakovskiy/37.htm>.

Mejerhol'd v russkoj teatral'noj kritike (2000), t. 2, 1920-1933, Moscou : A.R.T.

PICon-VAlLIN B. (dir.) (1997), Lioubimov, La Taganka, Paris : CNRS Éditions.

RUDNICKIJ Konstantin (1981), Mejerhol'd, Moscou : Iskusstvo.

ŠATRov Mikhail (1983), P'esy, Moscou : Sovetskij pisatel'.

SMELJANSKIJ Anatolij (2002), Uhodjaščaja natura (t. 2), Moscou : Iskusstvo.

Sovetskaja dramaturgija 1917-1940 (1983), Moscou : Prosveščenie.

Spektakli etih let 1953-1956g. Sb. Statej (1957), Moscou : Iskusstvo.

VAISSIÉ Cécile (2009), « Théâtre et politique dans l’URSS post-stalinienne : la "Léniniana" de Mikhaill Chatrov ", Chroniques slaves (Le XX ${ }^{e}$ siècle revisité), 5, 101-113.

VAISsIÉ Cécile (2012), « Le cinquantenaire de la révolution d'Octobre et la trilogie du théâtre Sovremennik », F. Maier-Schaeffer, C. Page \& C. Vaissié (dir.), La Révolution mise en scène, Rennes : PUR.

VIŠNEVSKAJA Inna (1988), « Leniniana. Pjatdesjat' let spustja », Sovremennaja dramaturgija, 1, 181-191.

ZoLOTNICKIJ David (1976), Zori teatral'nogo Obtjabrja, Léningrad : Iskusstvo.

ZolOTNICKIJ David (1999), Mejerhol'd. Roman s sovetskoj vlastju, Moscou : Agraf. 


\section{NOTES}

1. « Naš parovoz, vpered leti! / V kommune- ostanovka. / Inogo net puti- / V rukah vintovka »: refrain d'une chanson de komsomols cheminots, très populaire en URSS, interprétée pour la première fois le 7 novembre 1922 à Kiev.

2. V. Maïakovski, «Ordre à l'armée de l'art », 7 décembre 1918. "Prikaz po armii iskusstva », < www.stihi-rus.ru/1/Mayakovskiy/37.htm> (janvier 2018).

3. Les titres allégoriques en témoignent: Pantomime de la grande Révolution à Moscou, Hymne du travail libéré à Pétrograd, Lutte du Travail contre le Capital à Irkoutsk, La Marche des peuples libres à Kharkov.

4. Le caractère obligatoire de la célébration commence cependant dès le 23 octobre 1918 : ordre est donné à chaque collectif théâtral d'envoyer trois artistes pour fêter la révolution dans les théâtres du front.

5. Le balagan (théâtre de foire), le loubok (image gravée dans le bois du type de nos images d'Épinal) et le petrouchka (guignol russe, qui est la figure principale du théâtre de marionnettes) sont des formes spectaculaires jusque-là mineures que les artistes militants vont revaloriser.

6. Le premier numéro de Vestnik teatra, l'organe du département théâtral dont Meyerhold est alors le directeur, proclame dès le 27 janvier 1921 « la guerre civile au théâtre » et affirme : «Le théâtre bourgeois, cette véritable contre-révolution théâtrale, rassemble ses forces, enrôle une armée, lance une offensive et s'apprête à mener une guerre de position... Nous sommes en présence d'un front théâtral nettement défini. » Le 8 février 1921, après avoir fustigé l'hypnose de pseudo-traditions retenant le prolétariat dans les rets de l'idéologie bourgeoise et empêchant, de ce fait, la construction du communisme, les auteurs veulent imposer « une approche marxiste de l'art » pour laquelle la quête de nouvelles formes correspondant à l'actualité est nécessaire.

7. V. Majakovskij, Misterija Buff, Klop, Banja. P'esy, Moscou : Detskaja literatura, 1971, p. 30.

8. Cette pièce en vers, écrite en 1898 par le poète belge, attira l'attention en Russie en 1917, car elle montrait comment la guerre se transformait en insurrection populaire et pouvait préfigurer l'histoire de la révolution russe.

9. Dès lors, pour renouveler cette atmosphère de communion politique, les communiqués de l'Agence ROSTA ne seront plus affichés dans les couloirs mais lus sur la scène.

10. Nadežda Krupskaja, «Postanovka 'Zor' Verharna », dans Pravda, 10 novembre 1920, repris dans Mejerhol'd v russkoj teatral'noj kritike (2000: 5-6).

11. Parmi les pièces alimentant le culte de Staline au théâtre, on citera de K. Treniov, Sur les rives de la Neva ; de A. Korneïtchouk : La Vérité; de V. Vichnievski : L'Inoubliable année 1919.

12. Acte II, tableau 4. Voir Sovetskaja dramaturgija 1917-1940 (1983 : 307).

13. On citera parmi les pièces les plus fameuses sur la révolution et la guerre civile: Virineja de L. Seïfoulina, 1925, Théâtre Vakhtangov, mise en scène de A Popov ; Štorm / La Tempête de V. BillBelozerkovski, 1925, Théâtre MGSPS, mise en scène de E. Lioubimov-Lanskoï, Razlom / La Rupture de Lavreniov, 1927, Théâtre Vakhtangov, mise en scène de A. Popov, Lioubov Iarovaja de K. Treniov, 1926, Théâtre Maly, metteurs en scène I. Platon et L. Prozorovski.

14. Pour Train blindé, Stanislavski est revenu aux décors réalistes de Simov, qui avaient accompagné les débuts du Théâtre d'Art en 1898. Taïrov abandonne les tragédies antiques pour les drames sociaux de O'Neill.

15. «Chestidesiatniki » : jeunes intellectuels qui se manifestèrent dans les années 1960, après le XX ${ }^{\mathrm{e}}$ Congrès : ils aspiraient à la déstalinisation et à des réformes du système politique et social, sans le remettre en cause.

16. I. Solov'eva, "Hozjaeva vremeni [Les maîtres du temps]", dans le recueil Spektakli etih let 1953-1956g. Sb. Statej (1957 : 29). 
17. A. Smeljanskij, « Vzlet i krušenie Sovremennika », dans Efremov (1997 : 62-63).

18. Chatrov justifiait sa démarche en 1982 après avoir écrit Ainsi, nous vaincrons!: "Chaque génération d'artistes accomplit sa part de travail historique. En essayant de comprendre Lénine, nous nous interrogeons nous-mêmes à une étape donnée du développement de la révolution. En créant le portrait de Lénine, nous écrivons malgré nous notre autoportrait. » (Šatrov, 1983 : 247) 19. La pièce parut en janvier 1988. Finalement, Efremov refusera de monter la pièce de Chatrov, car il « aurait voulu s'attaquer aux racines de léninisme alors que Chatrov n'y était pas disposé » ( A. Smeljanski, « Novaja žizn' », dans Efremov, $1997: 83$ ).

20. G. Bordjukov: < https://ru.sputnik.md/columnists/20171031/15329785/9-mai-revolytianovoe-7-noabrea.html> (janvier 2018).

21. Chatrov, grâce à C'est ainsi que nous vaincrons ! obtint, à la place d'un appartement coopératif au métro Aéroport, un cinq pièces au centre de Moscou, dans la prestigieuse Maison sur le quai. Kaliaguine obtint lui aussi un appartement pour avoir joué le rôle de Lénine.

22. "Comment peut-on se moquer ainsi de la révolution? Qu'est-ce que ce cynisme ? Il faudrait fermer ce théâtre, quelle honte ! Où est le clair visage de Lénine ?» (Ljubimov, 2001 : 248)

23. I. Lioubimov, « Lettre à Leonid Brejnev », dans Picon-Vallin (1997 : 405).

24. A. Smelianski, «"Le Chêne et le veau”. Iouri Lioubimov et la société soviétique », dans PiconVallin (1997 : 37).

25. <www.5-tv.ru/news/164215/> (consulté en janvier 2018).

26. La Voie radieuse (Svetlyi put') est le titre d'un film de G.Alexandrov, une comédie musicale (1940) rythmée par «La Marche des enthousiastes" d'Issaak Dounaevski. Un autre spectacle, Le Cirque, créé en mai 2017 par M. Doudenko, reprend aussi le titre d'un des films préférés de Staline, une comédie musicale dans laquelle une artiste de cirque américaine tombe amoureuse d'un inventeur soviétique et part avec lui sur la lune... Ce spectacle, formellement très inventif, est d'une redoutable ambiguité puisqu'il reprend, sans ironie ni distance visibles, les chants patriotiques staliniens. En particulier, la chanson de Dounaevski et LebedevKoumatch: "Grande est ma patrie [...]. Je ne connais aucun autre pays où l'on respire aussi librement " y est magnifiquement orchestrée, chantée, et reprise par les acteurs devant un public enthousiaste qui applaudit à tout rompre...

27. La nouvelle Makar pris de doute date de 1929 ; Platonov venait d'apprendre que Tchevengour était interdit.

28. Kroupskaïa porte dans son ventre les ressources documentaires de la révolution qu'elle projette sur un écran à la demande, en ouvrant les pans de son manteau comme une exhibitionniste et retirant à la demande tel ou tel personnage.

\section{RÉSUMÉS}

Entre 1918 et 1989, les célébrations d'Octobre au théâtre ont engendré un genre particulier dans le cadre du "goszakaz», la commande d'État, au même titre que les spectacles dédiés à la problématique paysanne ou industrielle.

La première partie évoque la symbolique qui se met en place dans les principaux spectacles commémoratifs, depuis Mystère-Bouffe de Maïakovski / Meyerhold en 1918 en passant par les «léninianes» de N. Pogodine (L'Homme au fusil, 1937), V. Vichnievski (L'Inoubliable année 1919, 1950 ) et M. Chatrov à partir de 1967. Nous montrons quels enjeux ces spectacles ont représenté 
pour les auteurs, les acteurs, les metteurs en scène et la direction des théâtres et quelles transformations cette thématique a subies, depuis le culte du chef dans les années trente, sa critique au « dégel », jusqu'à la célébration obligée des années 1970 et 1980.

Nous relevons ensuite quelques discordances dans le chœur laudatif: après avoir évoqué les pièces de Boulgakov (Les Jours des Tourbine, La Fuite), les reprises avec variations des spectaclescultes (La Tragédie optimiste de Vichnievski, 1933 au Kamerny et en 1955 au BDT ; Les Carillons du Kremlin de Pogodine au Théâtre d'Art en 1942 et en 1957), nous nous arrêtons sur les audaces de Lioubimov à la Taganka avec l'adaptation scénique du livre de John Reed Les Dix jours qui ébranlèrent le monde en 1965.

Pour finir, nous constatons, après l'effervescence libératrice de la perestroïka, la disparition de pièces et spectacles commémoratifs dès la chute de l'URSS. Mais pour le centenaire de 1917, quelques spectacles auront fait le lien avec la révolution d'Octobre : La Leçon d'histoire (un gala donné au Mariinski), Octavia. Trépanation (un opéra contemporain de Kourlianski mis en scène par Iouri Ioukhananov) et La Voie radieuse adapté d'un film des années 1940 par le très jeune metteur en scène A. Molotchnikov.

Between 1918 and 1989, the theatrical celebrations of October Revolution have generated a special type of drama, in the context of the "goszakaz" (the state order), as well as the performances dedicated to the problematic of peasantry or industry.

The first part evokes the symbolic system that can be observed in the main commemorative shows since Mystery-Buff by Mayakovsky / Meyerhold in 1918, through the "leniniana" by N. Pogodin (Man with a Gun, 1937), V. Vichnievski (The Unforgettable Year 1919, 1950) and M. Chatrov, since 1967. We show what stakes these shows have represented for the playwriters, the directors and the heads of theatres, and what transformations this topic has undergone, since the Cult of the chief in the Thirties, its criticism during the "Thaw", until the unavoidable celebration in Seventies and Eighties.

We note then some discrepancies in the laudatory choir. After mentioning Bulgakov's plays, the remake with variations of the cult-dramas: The Optimistic Tragedy by Vichnievski, 1933 at Kamerny Theatre and in 1955 at BDT; The Kremlin Carillons performed in the Moscow Art Theatre in 1942 and 1957, we stop on The Ten Days That Shook the World, an scenic adaptation by Lyubimov of the John Reed's book in 1965 and we examine the main audacious ways of his performance.

Finally, we observe, after the liberating effervescence of the Perestroika, the end of commemorative dramas and shows. But for the centenary of 1917, a few shows will have made the connection with the Revolution: The Lesson of History (a gala given at Mariinsky), Octavia. Trepanation (a contemporary opera by Kourlianski directed by Yuri Ioukhananov) and A Radiant Road, adapted from a stalinist film by the very young director A. Molotchnikov.

\section{INDEX}

Mots-clés : révolution d'Octobre, théâtre soviétique, Meyerhold, Maïakovski, Pogodine, Chatrov, Vichnevski, «Léniniana », Lioubimov, « Octobre théâtral », spectacles de commémoration

Keywords : October Revolution, Soviet Theatre, Meyerhold, Mayakovsky, Pogodin, Chatrov, Vishnevsky, "Leniniana”, Lyubimov, "Theatre October", commemorative shows 


\section{AUTEUR}

\section{MARIE-CHRISTINE AUTANT-MATHIEU}

Marie-Christine Autant-Mathieu est directrice de recherches au CNRS, directrice adjointe de l'unité CNRS-Paris Sorbonne Eur'ORBEM, historienne du théâtre et spécialiste du théâtre russe et soviétique. Parmi ses dernières publications : Le Théâtre soviétique après Staline, Paris, IES, 2011 ; L'Étranger dans la littérature et les arts soviétiques (éd.), Lille, Septentrion, 2014 ; The Routledge Companion to Michael Chekhov (éd. avec Yana Meerzon), Londres / New York, Routledge, 2015, réédition complétée en 2018 ; K. Stanislavski, Correspondance, choix de textes, traduction, présentation, notes, Paris, Eur'ORBEM éditions, 2018.

Site web de l'auteur : <www.autant-mathieu.fr>. 